\title{
Consensus recommendation for meningococcal disease prevention for Hajj and Umra pilgrimage/ travel medicine
}

A. Shibl, ${ }^{1,2}$ H. Tufenkeji, ${ }^{3}$ M. Khalil, ${ }^{4}$ Z. Memish ${ }^{2,4}$ and the Meningococcal Leadership Forum (MLF) Expert Group

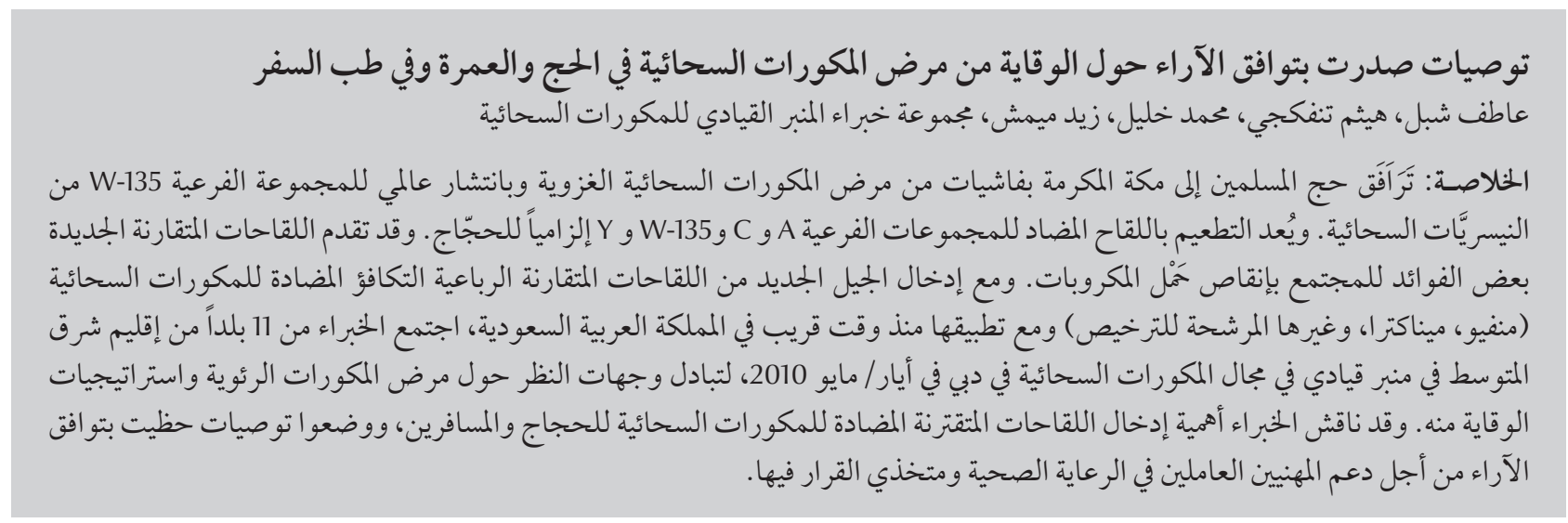

ABSTRACT The Islamic Hajj to Makkah (Mecca) has been associated with outbreaks of invasive meningococcal disease and the global spread of Neisseria meningitidis serogroup W-135. For Hajj pilgrims the quadrivalent vaccination against serogroups $\mathrm{A}, \mathrm{C}, \mathrm{W}-135$ and $\mathrm{Y}$ is a mandatory requirement. Novel conjugate vaccines may provide benefits for the community by reduction of carriage. With the introduction of the new generation of quadrivalent meningococcal conjugate vaccines (Menveo, Menactra, and others pending license) and their recent implementation in Saudi Arabia, experts from 11 countries in the Middle East region met at a Meningococcal Leadership Forum (MLF), in Dubai in May 2010 to exchange opinions on meningococcal disease and prevention strategies. These experts discussed the importance of introducing conjugate vaccines for pilgrims and travellers, and elaborated a consensus recommendation to support healthcare professionals and decision-makers.

Recommandations consensuelles sur la prévention de la méningococcie pendant les pèlerinages (Hadj et $O m r a)$ et sur la médecine des voyages

Le pèlerinage islamique (Hadj) à La Mecque a été associé à des flambées de méningococcies invasives et à la propagation mondiale de Neisseria meningitidis du sérogroupe W135. Pour les pèlerins du Hadj, le vaccin quadrivalent contre les sérogroupes A, C, W135 et Y est obligatoire. De nouveaux vaccins conjugués peuvent être bénéfiques pour la communauté en réduisant le nombre de porteurs. Avec l'introduction d'une nouvelle génération de vaccins antiméningococciques conjugués quadrivalents (Menveo, Menactra et autres licences en attente) et leur récente mise en œuvre en Arabie saoudite, des experts de 11 pays de la Région du MoyenOrient se sont réunis au Meningococcal Leadership Forum, à Dubaï, en mai 2010 pour échanger sur la maladie méningococcique et les stratégies de prévention. Ces experts ont discuté de l'importance d'introduire des vaccins conjugués pour les pèlerins et les voyageurs, et ont rédigé des recommandations consensuelles pour appuyer les professionnels de santé et les décisionnaires. 


\section{Introduction}

World-wide, most cases of meningococcal disease are caused by 5 of 12 known serogroups (A, B, C, W-135, Y) of Neisseria meningitidis. Asymptomatic carriage is common in the general population and can be as high as $35 \%$ [1]; during the Hajj, however, this can reach $86 \%$ [2]. There are several risk factors associated with bacterial carriage: crowded conditions (e.g. military barracks, dormitories, pubs, events), travel to endemic areas and personal behaviours (e.g. kissing, coughing, smoking) all increase exposure to the bacteria [1].

Even with appropriate treatment, the case fatality rate is high: $10 \%-30 \%$ depending on manifestation, age and serogroup $[3,4]$. Up to $20 \%$ of survivors suffer from permanent severe sequalae such as hearing loss, skin necrosis, seizures or limb amputation [3].

All 5 major serogroups of N. meningitidis exist everywhere at the same time, but relative proportions can vary greatly from country to country and can change unpredictably [5]. In Saudi Arabia, serogroup W-135 gained dominance within only 2 years [6], followed by other countries, e.g. Turkey, South Africa, Nigeria, Argentina, also observing much higher proportions of W-135 [7].

Travel is one of the major drivers influencing changing epidemiology. International travel can promote and accelerate the spread of different serogroups throughout the world, especially after mass gatherings such as the Hajj. In 2000 and 2001, serogroup W-135 was transferred from Hajj to other countries [6]. A comparison of the 2 outbreaks in Saudi Arabia in 2000 and 2001 shows the spread of disease outside the holy cities and an increase in cases in children $<5$ years [8], indicating that the use of polysaccharide vaccines after the first outbreak did not significantly reduce carriage or prevent transmission and infection in the unvaccinated.
Plain meningococcal polysaccharide vaccines are now considered to be outdated because of a number of important limitations [9]: they are not immunogenic in young children $(<2$ years); they do not elicit an immune memory and provide only limited duration of protection ( $\sim 3$ years); they have no significant impact on carriage and transmission; and they cannot be boosted - on the contrary, repeated polysaccharide vaccinations result in a reduced immune response (hyporesponsiveness). This has been demonstrated for serogroups C and W135 in African toddlers after PS vaccine compared to naive children [10].

In May 2010, experts from 11 countries in the Middle East region met at a Meningococcal Leadership Forum (MLF) in Dubai to exchange opinions on meningococcal disease and prevention strategies. They discussed the importance of introducing conjugate vaccines for pilgrims and travellers, and elaborated a consensus recommendation to support healthcare professionals and decision-makers.

A full background and description of transmission, burden of disease and changing pathogenicity as well as a comparison of polysaccharide and conjugate vaccines can be found in the consensus recommendations for prevention of meningococcal disease in children and adolescents that emanated from the Forum [11]. The current report presents the consensus-recommendation for meningococcal quadrivalent (ACWY) conjugate vaccination of pilgrims/ travellers. This manuscript covers parts and extracts of the previously published paediatric consensus paper [11].

\section{Consensus- recommendations}

\section{Meningitis and travel}

Neisseria meningitidis is the only bacterium that can generate widespread outbreaks and epidemics of meningitis
[12]. Owing to the high morbidity and mortality and the changing epidemiology, vaccination as broad as possible is recommended for prevention of meningococcal infections in travellers, particularly in pilgrims. While the incidence of infection in travellers to developing countries is about 0.5 per 100000 , it can be much higher in Hajj pilgrims (640 per 100000 ) and their contacts (up to 28 per 100000 ) and peaks during meningitis belt epidemics (up to 800 per 100 000) [13].

Current travel guidelines for prevention of meningococcal disease vary from country to country and according to the World Health Organization it is (only) generally recommended that vaccination should be considered for travellers to countries where outbreaks of meningococcal disease are known to occur [14]. However, for Hajj pilgrims and for travel to the extended African meningitis belt, quadrivalent vaccination is a mandatory requirement, and for travel to the extended African meningitis belt, a clear indication for meningococcal vaccination exists. Quadrivalent conjugate vace cines offer a broad serogroup protection and an assurance to prevent carriage. This would protect travellers as well as their contacts and could also be an important contribution to reduce the use of chemoprophylaxis, especially in those regions.

\section{Meningococcal outbreaks related to Hajj pilgrimage}

With globalization, pilgrim burden at the Hajj is set to rise as more people perform the pilgrimage each year. Currently, almost 3 million Muslims stay around the Holy Mosque in Makkah (Mecca) for at least 4-7 days [15]. The heavily overcrowded conditions during Hajj dramatically increase the transmission and carriage of airborne infectious agents because of prolonged stay (some people come for Umra and Ramadan and stay until Hajj, perhaps 2-3 months altogether), semi-permanent tents/ shared facilities, humidity and heat, and exhaustion from performing the Hajj 
rites (a large number of Muslims are elderly with poor health status).

The first large Hajj-associated meningococcal outbreak (1841 cases; serogroup A) occurred in 1987 and led to mandatory bivalent (AC polysaccharide) vaccination [16]. It was not until Hajj2000 that asecond, smaller, outbreak of meningococcal disease occurred with 253 cases in Saudi Arabia (more than one-third serogroup W-135; less than a quarter serogroup $\mathrm{A}$ ) with sustained community transmission [16]. Shortly after this more than $400 \mathrm{~W}-135$ cases were reported among returned pilgrims and their contacts from 16 countries world-wide $[16,17]$. All global isolates associated with this outbreak were of the single clone ET-37 (the most common clone causing epidemics), and the source of the strain was related to strains isolated in Mali, Algeria and Gambia in the 1990s [18]. In 2001, an additional outbreak (> $50 \%$ of cases were confirmed W-135) could not be prevented, mainly because not enough quadrivalent vaccine could be made available for the Ministry of Health to make it a Hajj requirement. Again, W-135 spread globally through international pilgrims, and in Saudi Arabia a large number of cases occurred among contacts of Hajjis. By May 2001 quadrivalent vaccination became a mandatory visa requirement for all pilgrims from any country. All national pilgrims as well as all residents of Makkah and Madinah (Medina) were vaccinated. Oral decolonization with ciprofloxacin prior to departure from the Hajj premises was strongly recommended to Saudi pilgrims and a national vaccination campaign for children was implemented [15]. Since the 2006/07 Hajj season, the prevention policy still recommends quadrivalent vaccine (not further specifying which technology) to all pilgrims and residents of the holy cities, and chemoprophylaxis ( 1 tablet of $500 \mathrm{mg}$ ciprofloxacin) for arriving pilgrims from the African meningitis belt, but no longer for pilgrims leaving the Hajj premises.
For the future, conjugate meningococcal ACWY vaccine should replace the polysaccharide vaccines that decrease immune response with repeated doses. This hyporesponsiveness is an important issue, especially for those who often perform Hajj/Umra and get vaccinated every $1-3$ years. Saudi Arabia decided to convert to ACWY conjugate vaccines by 2010 , starting with the following target populations: all national pilgrims, all people working in the Hajj areas and all residents of Makkah and Madinah.

\section{Consensual recommendation for ACWY conjugate vaccination}

The experts of the Middle East region agreed on the concept of using conjugate vaccines, replacing polysaccharide vaccines. The overall consensus was that conjugate vaccines are the best choice for prevention of meningococcal disease, in particular because of the added value for the community: The potential of stopping transmission by prevention/clearance of carriage offers the possibility to protect the contacts of vaccinees and prevents dissemination of the bacteria to other countries. In many countries the experience is made that meningococcal infections still occur (especially at the contacts around Hajjis) despite high coverage of polysaccharide vaccination among pilgrims. Therefore the impact of conjugate vaccines on carriage is of major interest - from epidemiologic, economic and also from public health perspective, as each single case of meningococcal disease, no matter if imported or indigenous, requires a public health response (i.e. identification of close contacts for prophylaxis). It is assumed, that this class-effect of conjugate vaccines also applies to quadrivalent meningococcal conjugate vaccines, although confirming data of course are not yet available for the new vaccines. Due to the fact that Hajj pilgrims often are of older age, it is reassuring that conjugate ACWY vaccines in the age group of 56 to 65 years of age resulted in higher percentage of seroresponders for all serogroups, compared to polysaccharide vaccine [19].

Another important benefit is the chance of getting the "overuse" of antibiotics under control: If the use of conjugate vaccines becomes widespread, there will be no more or at least much less need for chemoprophylaxis. A remaining concern in this context is, that also the conjugate ACWY vaccines do not cover all serogroups (B, X).

\section{People who should be vaccinated with ACWY conjugate vaccination}

These include:

- all Hajj and Umra pilgrims (especially when Umra is performed in peak times such as Ramadan);

- travellers to the extended African meningitis belt;

- travellers to countries where outbreaks are known to occur or with epidemic risk;

- military and national guard;

- health-care workers in countries with a high burden of disease (especially those working in intensive care units, laboratories, paediatric ward);

- health-care workers, policemen and other personnel in the Makkah and Madinah area as well as in airports and seaports that receive pilgrims;

- participants of exchange programmes (pupils, students, au-pairs, expatriate workers) before long-term stays in countries with recommended meningococcal immunization, if required by host institution;

- high-risk groups (e.g. the elderly; immunodeficient patients).

\section{Recommended implementation strategy}

In general, conjugate vaccine should replace plain polysaccharide vaccines. Start with high-risk groups (primarily pilgrims) and continue going down. 
Owing to the fact that plain polysaccharide vaccines induce hyporesponsiveness, consideration should be given to ensuring that anyone being vaccinated for the first time (i.e. polysaccharidenaive persons) gets a conjugate vaccine.

For the transition period, when both types of vaccines are still available and polysaccharide vaccines will be used in parallel, one could consider to give it preferentially to older populations who will go to Hajj only once in lifetime and who do not travel frequently.

For pilgrims at least it should be ensured that everyone coming for Hajj or Umra is vaccinated against ACWY meningococci, prioritizing conjugate vaccines as early as available. At present the use of ACWY conjugate vaccines is limited to the registered age-ranges $[2+$ years or $11+$ years for
Menveo (depending on the country), 9 months -55 years for Menactra].

For certain countries the costs of conjugate vaccines may be a problem at introduction, but these will be recovered within a few years through the potential for prolonged protection and herd immunity (which has to be demonstrated by clinical studies). Costs really need to be considered in relation to benefits; after some years, and with widespread use, conjugate vaccines may even be cost-effective.

There are many questions to be answered in the coming years, nevertheless the concept of conjugate vaccines offers convincing and significant progress in preventing meningococcal disease, treatment for which is always is a race against time and immediate appropriate medical care may not be available everywhere.
Acknowledgements

The authors would like to thank the following experts of Novartis Vaccines for scientific contribution to the conference: Wolfgang Bender, MD, Michael Bröker, PhD, Brian Cooper, MD, Claudius Malerczyk, MD, Joshi Venugopal, MD. Additionally, the authors thank Irene Pemp of IP-Pharma agency for medical writing support with the preparation of this manuscript.

Funding: The Meningococcal Leadership Forum was organized and financially supported by Novartis Vaccines. An unrestricted grant for this manuscript was provided by Novartis Vaccines. Opinions expressed are those of the authors. None of the authors have received any honorarium.

\section{References}

1. Brigham KS, Sandora TJ. Neisseria meningitidis: epidemiology, treatment and prevention in adolescents. Current Opinion in Pediatrics, 2009, 21(4):437-443.

2. Al-GahtaniYM et al. Epidemiological investigation of an outbreak of meningococcal meningitis in Makkah (Mecca), Saudi Arabia, 1992.Epidemiology and Infection, 1995, 115(3):399-409.

3. Bilukha OO, Rosenstein N; National Center for Infectious Diseases, Centers for Disease Control and Prevention (CDC). Prevention and control of meningococcal disease. Recommendations of the Advisory Committee on Immunization Practices (ACIP). MMWR. Recommendations and Reports, 2005, 54RR-7:1-21.

4. Trotter $\mathrm{CL}$, Ramsay ME. Vaccination against meningococcal disease in Europe: review and recommendations for the use of conjugate vaccines. FEMS Microbiology Reviews, 2007, 31:101-107.

5. Khatami A, Pollard AJ. The epidemiology of meningococcal disease and the impact of vaccines. Expert Review of Vaccines, 2010, 9(3):285-298.

6. Khalil MK, Borrow R. Serogroup B meningococcal disease during Hajj: preparing for the worst scenario. Travel Medicine and Infectious Disease, 2009, 7(4):231-234

7. Von GottbergA et al.; Group for Enteric, Respiratory and Meningeal Disease Surveillance in South Africa. Emergence of endemic serogroup W135 meningococcal disease associated with a high mortality rate in South Africa. Clinical Infectious Diseases, 2008, 46(3):377-386.

8. Infectious diseases report. Riyadh, Ministry of Health, 2008.

9. Harrison LH. Prospects for vaccine prevention of meningococcal infection. Clinical Microbiology Reviews, 2006, 19(1):142-164.

10. Findlow $\mathrm{H}$ et al. Meningococcal group $\mathrm{C}$ and w135 immunological hyporesponsiveness in african toddlers. Clinical and Vaccine Immunology, 2011, 18 (9):1492-1496.
11. Shibl A et al.; The Meningococcal Leadership Forum Expert Group. Consensus recommendation for meningococcal disease prevention in children and adolescents in the Middle East region. Journal of Epidemiology\& Global Health, 2012, 2(1):23-30.

12. Girard MP et al .A review of vaccine research and development: meningococcal disease. Vaccine, 2006, 24(22):46924700.

13. Wilder-Smith A. Meningococcal vaccines: a neglected topic in travel medicine? Expert Review of Vaccines, 2009, 8(10):13431350.

14. International travel and health 2010. Geneva, World Health Organization, 2010, Chapter 6:117-119 (http://www.who.int/ ith/en/, accessed 24 June, 2010).

15. Memish ZA, Venkatesh S, Ahmed QA. Travel epidemiology: the Saudi perspective. International Journal of Antimicrobial Agents, 2003, 21(2):96-101.

16. Lingappa JR et al. Serogroup W-135 meningococcal disease during the Hajj, 2000. Emerging Infectious Diseases, 2003, 9(6):665-671.

17. Hahné SJ et al. W135 meningococcal disease in England and Wales associated with Hajj 2000 and 2001. Lancet, 2002, 359(9306):582-583.

18. Mayer LW et al. Outbreak of W135 meningococcal disease in 2000: not emergence of a new W135 strain but clonal expansion within the electophoretic type-37 complex. Journal of Infectious Diseases, 2002, 185(11):1596-1605.

19. Stamboulian D et al. Safety and immunogenicity of an investigational quadrivalent meningococcal CRM(197) conjugate vaccine, MenACWY-CRM, compared with licensed vaccines in adults in Latin America. International Journal of Infectious Diseases, 2010, 14(10):e868-e875. 